\title{
The BuRden OF DECIDING For YouRSELF: The Disutility CAUSED By OUT-OF-PoCKeT HEALTHCARE SPENDING
}

Christopher T. Robertson ${ }^{*}$ and David V. Yokum ${ }^{* *}$

I. INTRODUCTION

II. MaPPInG The NoRmative ObJECTIONS To Cost-

SHARING

A. Underinsurance

B. Reductions in High-Value Healthcare ...................613

C. The Unfair Tax on Sickness..................................615

D. Decisional Burden ................................................617

III. The Alternatives To Cost SHARING ............................618

A. Alternative World\#1: Outsourcing the Rationing

Function

B. Alternative World \#2: Forgo Rationing ...................621

IV. EVAluating THE DeCisional BURDEN ........................622

A. Choice Overload....................................................623

B. Depletion of Cognitive Capacity ............................627

C. Facilitation of Regret ...........................................631

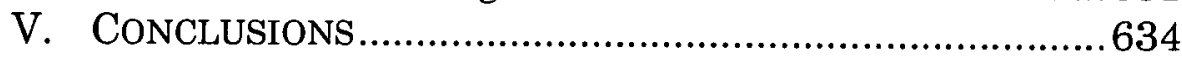

As part of a larger "consumer-directed healthcare movement," cost-sharing mechanisms, such as copays and deductibles, cause patients to pay out of pocket for a portion of the costs of the healthcare they consume. Cost sharing is

* JD, $\mathrm{PhD}$, associate professor at the James E. Rogers College of Law, University of Arizona. Robertson wrote this piece while a visiting professor at Harvard Law School. $\mathrm{He}$ may be reached at crobertson@post.harvard.edu. This paper is part of a symposium on "Patient's Responsibility for Health Care," and the authors thank the organizers, including the student editors and professors Nicolas Terry and David Orentlicher, who kindly invited us to participate.

** JD, MA, MA, doctoral student in Psychology at the University of Arizona and a fellow of the U.S. Social and Behavioral Sciences Team. The opinions expressed in this paper are those of the authors in their individual capacities. 
intended to reduce costs by changing consumption behavior, and it has been shown to be an effective though incomplete solution to the problem of unsustainable cost growth. It is controversial nonetheless. This Essay distinguishes three different normative problems with cost sharing (including underinsurance, deterrence of high-value care, and a tax on sickness), which can all be fixed through more precision in the design of cost-sharing mechanisms.

This Essay provides the first sustained investigation of a fourth problem, "the decisional burden." By setting aside the three foregoing problems and then carefully specifying two alternative counterfactual situations in which costsharing obligations are removed, the analyst can precisely identify the remaining causal impacts of cost sharing, namely: a subjective disutility experienced by patients when navigating a difficult, and potentially unwanted, choice amongst a complex set of options, requiring tradeoffs between health and wealth. Several concepts from the behavioral sciences-cognitive capacity, choice overload, sunk costs, and regret-shed light on this problem. This Essay reviews select portions of that literature and concludes that the decisional burden is a real disadvantage of using patient cost sharing as a mechanism for rationing healthcare. Advocates of cost sharing must bite this bullet.

Nonetheless, the behavioral science results are descriptive, not prescriptive. In a world of epistemic uncertainty and heterogeneity of values, it is not irrational for consumers to prefer cost-sharing-if carefully designed and implemented-as the least-bad rationing mechanism among the alternatives, which either reduce access to healthcare or sink costs for unwanted healthcare. Ultimately, the burden of deciding for yourself is the burden of being an autonomous person.

\section{INTRODUCTION}

Over the last several decades, deductibles, copays, coinsurance, reference pricing, and other forms of cost sharing have become a primary tool to reduce the cost of 
health insurance. ${ }^{1}$ Cost sharing has both a distributional function (as to how much the insurer versus the patient pays at the point of consumption), and a behavioral function (as to whether the patient chooses to consume versus decline certain healthcare). ${ }^{2}$ The behavioral function is a form of distributed rationing, since it asks the patient to determine whether the healthcare in question is worth the cost exposed to the patient. If cost sharing can reduce consumption of healthcare, or shift patients towards less expensive forms of healthcare, it may then reduce the cost of insurance premiums ex ante. It may also counteract some of the pro-consumption biases that currently exist in the healthcare system, making the economy more efficient, as individuals trade for other healthcare and other forms of non-healthcare consumption that deliver higher value. ${ }^{3}$

The increasing use of cost sharing has been controversial, however. There are practical problems with making cost-sharing work, most notably the lack of pricetransparency in the American healthcare market. 4 If patients are unaware of the exposed costs associated with each treatment option, they are then unable to perform the cost-benefit analysis that cost sharing presumes. States are legislating, federal officials are investigating, and entrepreneurs are starting new enterprises, all seeking to improve this situation.

I KAISER FAMILY Foundation, EMPloyer HEALTH BENEFITS 2012 ANNUAL SURVEY 4 [hereinafter KFF 2012 SURVEY], available at http://kff. org/private-insurance/report/employer-health-benefits-2012-annual-survey/ ("Most covered workers face additional plan costs when they use health care services."), archived at http://perma.cc/UYV7-HS7N.

2 Christopher T. Robertson, Scaling Cost-Sharing to Wages, 14 YALE J. HEALTH POL'Y L. \& ETHICS (forthcoming 2014).

3 Christopher Robertson, The Split Benefit: The Painless Way to Put Skin Back in the Healthcare Game, 98 CORNELL L. REV. 921 (2013).

4 See Uwe E. Reinhardt, The Pricing of US Hospital Services: Chaos Behind a Veil of Secrecy, 25 HEALTH AFF. 57 (2006); Peter A. Ubel et al., Full Disclosure - Out-of-Pocket Costs as Side Effects, 369 NEW ENG. J. MED. 1484 (2013) (arguing that physicians have a duty to provide such price information to patients, and discussing state legal mandates for price transparency). 


\section{MAPPING THE NORMATIVE OBJECTIONS TO COST-SHARING}

From a normative perspective, there are four primary objections to cost sharing. Most of these are objections to the relatively crude design of extant cost-sharing policies, which may be addressed by contemporary and future reforms. The final concern about subjective disutility is our focus here, but it is best understood in contradistinction to these other concerns.

\section{A. Underinsurance}

An initial concern is that cost sharing may be so large in comparison to the patient's wealth that it undermines the core functions of insurance, namely, guaranteeing access to care and protection from financial risk. ${ }^{5}$ After all, cost sharing is just a way of saying that the patient retains exposure to some of the risk of illness. This phenomenon is called "underinsurance": if patients cannot afford the costsharing burden imposed by their health insurance problems, then they effectively lose access to the healthcare, or they stretch and find themselves in bankruptcy or foreclosure. ${ }^{6}$

5 See generally M. Gregg Bloche, Consumer-Directed Health Care and the Disadvantaged, 26 HEALTH AFF. 1315, 1318 (2007).

6 See Rashid Bashshur et al., Defining Underinsurance: $A$ Conceptual Framework for Policy and Empirical Analysis, 50 MED. CARE REV. 199 (1993); Cathy Schoen et al., How Many Are Underinsured? Trends Among U.S. Adults, 2003 and 2007, 27 HEALTH AFF. w298 (2008), http://content.healthaffairs.org/content/27/4/ w298.full.pdf, archived at http://perma.cc/7CW9-YWFR; David U. Himmelstein et al, Medical Bankruptcy in the United States, 2007: Results of a National Study, 122 AM. J. MED. 741, 744-45 (2009) (finding that $62 \%$ of bankruptcies had medical causes, including but not limited to out-of-pocket spending, and that of $78 \%$ of those filers had medical insurance at the start of their illness); see also Tal Gross \& Matthew J. Notowidigdo, Health Insurance and the Consumer Bankruptcy Decision: Evidence from Expansions of Medicaid, 95 J. PUB. ECON. 767 (2011) (a quasi-experimental study finding that out-of-pocket medical costs roughly account for $26 \%$ of personal bankruptcies among low-income households); Christopher Robertson et al.,. Get Sick, Get Out: The Medical Causes of Home Foreclosures, 18 HEAlTH MATRIX 65, 90-94 (2008) (survey finding that more than half of foreclosures had medical causes). 
Such financial distress may also lead to psychological stress and related problems. If difficulty paying is correlated with class, race, or ethnicity, then this underinsurance problem may also exacerbate disparities in healthcare. ${ }^{7}$

In other work, Robertson has suggested two ways in which this very serious problem can be addressed through careful design of cost-sharing policies. First, insurers can scale cost-sharing obligations to the wealth of individual beneficiaries, so the remaining exposed risk is proportionate to the ability of patients to bear that risk. ${ }^{8}$ Second, for very expensive treatments and for poorer patients, cost sharing can still be used, without creating underinsurance, through a novel design that we have elsewhere proposed and tested. The insurance benefit can be "split" between the patient and the provider, so a portion is transferred as wealth to the patient, who pays that portion to the provider upon choosing to consume. This "split benefit" thus forms a costsharing obligation and-most importantly-an opportunity cost, which does not depend on the patient's own prior wealth. ${ }^{9}$ At least analytically, these sorts of potential solutions to the underinsurance problem allow a sharper focus on the other problems associated with cost sharing.

\section{B. Reductions in High-Value Healthcare}

A second concern is that, in addition to its intended behavioral function of discouraging consumption of low ${ }^{-}$ value healthcare, cost-sharing obligations may cause patients to decline beneficial healthcare that they would be better off consuming. 10 This objection is essentially paternalist. ${ }^{11}$ The problem has been observed in empirical

7 See Bloche, supra note 5, at 1316.

8 See generally Robertson, supra note 2.

9 See generally Robertson, supra note 3.

10 See KATHRYN SWARTZ, ROBERT WOOD JOHNSON FOUNDATION RESEARCH, RESEARCH SYNTHESIS REPORT No. 20, COST-SHARING: EFFECTS ON SPENDING AND OUTCOMES 1 (2010); Dahlia K. Remler \& Jessica Greene. Cost-Sharing: A Blunt Instrument, 30 ANN. REV. PUB. HEALTH 293 (2009).

11 Einer Elhague, Allocating Health Care Morally, 82 CAL L. REV. 1457,1480 (1994) (discussing that paternalism "actually motivates 
research, most notably the RAND Health Insurance Experiment. Cost sharing reduced consumption of healthcare that analysts coded "high value," along with the healthcare they coded as "low value." However, for the median patients, the declining of such "high-value" care does not consistently worsen health outcomes. ${ }^{12}$ That disconnect between consumption behavior and health outcomes suggests that the declined "high-value" care may not have been so worthwhile after all. Still, for the subset of participants who were poorest, the cost-sharing burden caused an even greater reduction in consumption of seemingly "high-value" care, and did worsen health outcomes. Thus, this problem may also be a species of the underinsurance problem.

To the extent that this objection is distinct from the prior one, it must be assumed that the cost-share is perfectly affordable. The distinct point is that even patients who can perfectly well afford to pay the cost share may nonetheless fail to make the optimal consumption decisions, due to their exposure to that price. From a theoretical perspective, cost sharing often exposes patients to only a small portion of the costs of healthcare ( $18 \%$ is a typical coinsurance rate), so this normative concern must presume that patients make radical errors towards non-consumption when making the cost-benefit tradeoffs (supposing that even $18 \%$ of the costs outweigh the benefits). ${ }^{13}$ Robertson has argued elsewhere that we generally lack the epistemic and normative basis to make such a paternalistic critique of patients' decisions to decline care. ${ }^{14}$ Especially for the 5\% of most expensive healthcare, which drives most aggregate healthcare spending, a policy analyst simply cannot say that the benefits of the declined healthcare would have exceeded its costs and risks. Indeed, we should presume the contrary.

policymakers to refuse to simply redistribute cash: the poor, many believe, would irrationally spend money on the wrong things").

12 JoSEPH P. NEWHOUSE, FREE FOR ALL? (1993).

13 See KFF 2012 SURVEY, supra note 1, at 121, Exh. 7-21 (showing the $18 \%$ figure).

14 Christopher T. Robertson, A Presumption Against Expensive Healthcare Consumption, 49 TULSA L. REV. 627 (2014). 
Thus, this paternalist critique bears a heavy burden of persuasion that is rarely met.

Nonetheless, in such cases where that burden has been met-such as where it is important that patients adhere with a proven drug regimen-this problem can also be addressed through careful insurance design. In recent years, scholars have developed a "value-based insurance" model, in which costs sharing is reduced or eliminated for healthcare that is known to be beneficial to the patient and cost saving on net. ${ }^{15}$ Thus, in cases where we know that healthcare should be consumed, cost sharing can and should be simply waived.

\section{The Unfair Tax on Sickness}

A third normative concern is that cost sharing is unfair to those who are sick because it disproportionately places upon them the burden of paying for sickness in a society. If one conceives of sickness as simply an unlucky draw from the genetic lottery, or a broader lottery that includes other disease vectors, then it may seem unfair for sick individuals to bear part of their own healthcare costs, while the luckily healthy bear no such costs. Here, sickness is understood as a social burden not an individual burden. ${ }^{16}$ This is potentially a profound objection because it draws upon fundamental conceptions of justice and the purpose of insurance.

A complete analysis of this objection is not possible here, but a few points are worthwhile. First, of course, not all sickness is caused by random factors. Lots of healthcare

15 Michael Chernew et al., Value-Based Insurance Design, 26 HEALTH AFF. w195, w195-w196 (2007).

16 See Allison K. Hoffman, Three Models of Health Insurance: The Conceptual Pluralism of the Patient Protection and Affordable Care Act. 159 U. PA. L. REV. 1873, 1922-32 (2010) (discussing "brute luck" theories of health insurance). For a proponent of such a theory, see, e.g., Shlomi Segall, Is Health (Really) Special? Health Policy Between Rawlsian and Luck Egalitarian Justice, 274 J. APPLIED PHIL. 344 (2010) (arguing for public funding of breast reduction surgery, skin color change treatments, gender reassignments, and even surgery to allow male pregnancy, if possible). 
expenses are driven by choices individuals make for themselves. As long as cost sharing is driven by prospective behavioral justifications, rather than theories of moral desert, we need not untangle this problem of mixed causes. But those who raise this profound critique of cost sharingsaying that the burden is undeserved (always or in certain situations)-would need to untangle these causes. ${ }^{17}$

Second, cost sharing only imposes a small portion of healthcare expenses on the individual sick patients; the remainder of the expenses are redistributed to the other members of the insurance pool. Overall, in the typical employer-sponsored plan (the primary source of insurance in the United States), the employees bear about $7 \%$ of the cost of healthcare at the point of consumption; the remaining $93 \%$ is borne by the insurer. ${ }^{18}$ Thus, the sick do receive a huge redistribution (subsidy) that compensates for their unluckiness. That is the very purpose of insurance: to redistribute risk.

Third-and most importantly-if an insurer solves the underinsurance problem discussed above, so that each individual is exposed only to the amount of risk that is bearable, it is hard to motivate a theory of justice that would require redistribution of bearable risks. After all, individuals are exposed to all sorts of bearable risks in the modern society-everything from the mundane risks, such as the need for plumbing repair or roadside assistance for a flat tire, to more substantial risks, such as having the value of one's house decrease. Americans do not typically suppose that justice requires that these risks be redistributed, at least as long as they are small enough to be bearable. For these reasons, it seems that this "unfair tax on sickness" objection is a species of the underinsurance objection, which can and should be resolved through more precise design of insurance policies. ${ }^{19}$

17 See Dan Wikler, Who Should be Blamed for Being Sick?, 14 HEALTH EDUC. \& BEHAV. 11 (1987).

18 Chris Peterson, Cong. Research Serv., R4049, SETTING AND VALUING HEALTH INSURANCE BENEFITS (2009).

19 Similarly, see Bloche, supra note 5, at 1325 ("Medical coverage is more than a business proposition; it is an expression of our 


\section{Decisional Burden}

A fourth concern is our focus here. Even if patients can afford the cost-sharing burden (which is to say that they are not underinsured), it may still be stressful and otherwise psychologically burdensome for patients to think about those costs when making decisions, or to even actively engage in the making of decisions at all, rather than simply deferring to their physicians. Out-of-pocket expenses may make healthcare decisions more difficult, in part because it adds a criterion that is possibly incommensurate with the others being considered. Bruce Vladek has suggested such an analysis:

Consumers ... don't wish to be forced to make rational trade-offs when they are confronted with medical care consumption decisions. [M] edical care is about living and dying, something considered by many to be of a rather different character from the purchase of tomatoes. The primary characteristic of most consumers of medical care most of the time is that they are scared. They are scared of dying, or disfigurement, or permanent disability; and these are serious matters. ${ }^{20}$

In this sense, a cost-sharing burden makes the patient's healthcare decisions-which are already profoundly difficult, as they are made in the grips of scientific uncertainty with existential questions about whether and how to live-even more difficult. This difficulty can lead to stress, lack of certainty, cognitive load, and other disutility. Although mentioned by several scholars and commentators, this "decisional burden" concern has tended to be conflated with other concerns about cost sharing, and, thus, received

commitment to each other. Cost sharing that renders high-value care unaffordable breaches this commitment") (emphasis added).

20 Bruce Vladeck, The Market $v$. Regulation: The Case for Regulation, 59 MiLBANK Q. 209, 210-11 (1981). 
virtually no sustained investigation of its own. ${ }^{21}$ It is our focus here.

\section{The Alternatives to Cost ShaRING}

To weigh this concern about decisional burden in the domain of bearable costs, a policymaker or an insurance buyer would need to compare the disutility associated with decisional burden with the costs of alleviating that burden. The amount of disutility is an empirical question explored below, one that will likely vary across patients and across the various sorts of treatment decisions that will be made.

To understand whether, how, and to what extent cost sharing actually creates decisional burden disutility, it is useful to identify the counterfactual world that would obtain without cost sharing. We have suggested above that cost sharing is a form of "rationing," since it asks the patient to determine whether the healthcare in question is worth the cost exposed to the patient. In principle, there are two different ways that the decisional burden could be eliminated: (a) outsource the rationing function, which will likely reduce the choice set of treatments available to the patient at the point of consumption; or (b) stop rationing altogether and thereby increase the costs of insurance premiums (or tax outlays) ex ante. We consider each below.

\section{A. Alternative World \#1: Outsourcing the Rationing Function}

The first alternative to cost sharing is to outsource the rationing function to someone else-whether it is the physician, the insurer, a government regulator, or some third party to receive the pricing information and then decide whether the treatment's benefits to the patient are worth its cost to the insurer. ${ }^{22}$ There are then two ways to conceive the rationer's mission.

21 See generally SWARTZ, supra note 10; Remler \& Greene, supra note 10.

22 This is no easy task. See Einer Elhauge, The Limited Regulatory Potential of Medical Technology Assessment, 82 VA. L. REV. 
One way is that the optimal rationer could be given the mission of replicating the decisions that the individual principal would have made if he or she had been exposed to price. This is similar to one conception of the way healthcare proxies are supposed to work for incompetent patients. ${ }^{23}$ In this "patient proxy" conception of rationing, the rationer would hold the cost of insurance premiums constant (since consumption is unchanged from the costsharing world) plus some additional marginal cost for paying for the services of the rationer. Those marginal costs could be quite high since the rationer is providing decisions customized to the personal values and clinical situations of each individual patient. On this conception of the outsourced rationer, the patient's personal autonomy is theoretically infringed because he or she is denied other options, but the denial is trivial if we assume arguendo that the rationer properly predicts that he or she would not have chosen those other options anyway.

Of course, such a conception of the outsourcing of the rationer's mission is complicated by principal-agent problems. In the weighing of costs and benefits, it may be difficult to align the decisions of those rationers with the patient's own interests. For example, if the rationer is affiliated with the insurer, the rationer may be more concerned with the costs of treatments than their benefits to the patient. ${ }^{24}$ More fundamentally, even if properly motivated, it may be difficult for the rationing agents to assess the principal's individualized interests and values. ${ }^{25}$

1525 (1996) (describing the profound normative and epistemic difficulties); Robertson, supra note 3, at 921, 931-43 (2013) (explaining the problems with physician rationing and insurer rationing).

23 See Tom L. Beauchamp \& James F. Childress, "Respect for Autonomy", in PRINCIPLES OF BIOMEDICAL ETHICS 120-88 (4th ed. 1994).

24 See Mark A. Hall \& Gerard F. Anderson, Health Insurers' Assessment of Medical Necessity, 140 U. PA. L. REV. 1637, 1668 (1992). See generally JAY M. FEINMAN, DELAY, DENY, DEFEND: WHY INSURANCE COMPANIES DON'T PAY ClaIMS AND What YOU CAN Do ABOUT It (2010) (discussing insurers' tactics of delaying or denying justified claims and forcing policyholders to litigate).

25 See Einer Elhauge, Allocating Health Care Morally, 82 CAL. L. REV. 1450 (1994) (suggesting that a diversity of insurance plans could 
More realistically, then, the rationer would likely not follow such a patient-proxy algorithm. Instead (and this is the second conception), the rationer would use its own costbenefit assessments, and then create a subset of all possible treatment options that survive the rationing test. This reduced menu would be presented to the patient for binary choices of whether to accept or decline on the basis of nonfinancial considerations. This solution has the immediate consequence of reducing the patient's autonomy and access to healthcare, since there will be instances in which the outsourced rationer excludes treatments from the choice set (i.e., declines care) that the patient him or herself would have preferred to consume. Often, indeed, the patient's choice set will be reduced to a single option, which the patient can take or leave. If the decisional burden were very severe, it may be rational for a person to make such a trade ex ante, giving up some control over healthcare decision making in order to avoid the burdens of exercising that control.

It is also possible that this rationer will on net decline more (or less) care than the patients would have done under a world of cost sharing, which, thus, could cause insurance premiums to go down (or up). Assuming, however, that the rationer is roughly accountable (through democratic or market mechanisms), let us suppose the premiums are held constant. It is also possible that an outsourced rationer would make better decisions on the merits than patients would make for themselves. ${ }^{26}$ This phenomenon would be a species of the second problem, set aside above. ${ }^{27}$

be created, reflecting different rationing priorities, from which insurance buyers could select ex ante); see also Russell Korobkin, Comparative Effectiveness Research as Choice Architecture: The Behavioral Law and Economics Solution to the Health Care Cost Crisis, 112 MICH. L. REV. 523 (2013) (similar).

26 See George Loewenstein et al., Can Behavioural Economics Make Us Healthier? 344 BMJ 1, 2 (2012) (discussing Britain's National Institute for Health and Clinical Excellence (NICE), "which makes national decisions regarding the cost effectiveness of treatments and ensuing coverage" as an example of a "good shove that advances individual and social welfare considerably more" than a nudge).

27 See Part II.B above. 


\section{B. Alternative World \#2: Forgo Rationing}

The second alternative is to loosen the constraint on insurance premiums and forego the price signal rationing function altogether. As Vladek has suggested, "[a]s a society, we may be prepared to pay a substantial economic premium to insulate people from having to make such decisions." 28 Under such a policy, the patient could consume any healthcare she desired with absolutely nobody paying attention to its cost.

Under this regime, the cost of health insurance premiums would, thus, be higher than in situations where someone is performing the rationing function. The insurance premiums would be inflated in two ways: first, more healthcare would be consumed, and second, the producers and providers of that healthcare would significantly increase their prices charged since they would not be competing along the dimension of price. These higher prices might make health insurance unaffordable $e x$ ante or, even if affordable, would force tradeoffs between other spending priorities (e.g., housing or nutrition) against the marginally higher health insurance premiums. In this sense, insurance creates a sunk cost: the patient pays ex ante for healthcare that she would not choose to consume ex post if she had to bear those costs at the point of consumption. This is a waste, which is a prima facie harm to the consumer. ${ }^{29}$

For present purposes, let us set aside redistributional policies and assume that the patient bears these ex ante costs, which implies that he or she has less disposable

28 See Vladek, supra note 20, at 212.

29 Moral hazard is the problem that the fully insured purchaser bears none of the costs at the point of consumption. If consumers conceive of their health insurance as a prepayment of a right to consume healthcare, then it may also give rise to the sunk cost fallacy. Under this fallacy, a consumer is more likely to consume, potentially even selecting an otherwise suboptimal choice, based on the sense that her own prior investment would be wasted if she did not consume the pre-purchased goods. We are unaware of these two potential confounding effects being disambiguated in the health insurance domain. 
wealth at the point of consumption. Nonetheless, let us also assume that insurance is somehow sustainable even without rationing, so we can hold coverage constant for the individual. These assumptions may not be realistic for all patients, of course.

\section{Evaluating the DeCisional BURDEN}

To summarize the prior Part: In the first alternative to cost sharing, the rationing decision is outsourced, and, then, the patient makes consumption decisions-among a potentially reduced choice set-without regard to the price. In many instances, the patient will have no choice among alternative treatments at all. In the second alternative to cost.sharing, a patient makes consumption decisions without regard to price and has a full range of choices but, also, less wealth.

In light of these counterfactuals, research from the behavioral sciences, notably the field of judgment and decision-making, sheds light on the decisional burden potentially associated with cost-sharing mechanisms. We review some of this literature, trying to draw analogies to cost sharing, and drawing on the medically related literature in particular. Notably, however, we have found no direct study of these phenomena in the cost sharing setting in particular.

The burden might be exacted in at least two forms: first, the quality of the decision itself might be worsened, and, second, even if choice quality is not objectively worsened, the decision maker may come to personally feel less satisfied with the choice. We approach these issues from several angles. We begin by considering how features of the choice set affect decision-making. Specifically, additional choices can, somewhat paradoxically, actually worsen decision quality and satisfaction. We then turn to consider characteristics of the decision maker. Our case study is cognitive capacity and, in particular, how consideration of stressful financial constraints can itself deteriorate cognitive performance. Finally, we examine how 
outsourcing a decision avoids the potential for regret, especially of a self-blame variety.

\section{A. Choice Overload}

Outsourcing the rationing function has the ultimate effect of reducing the number of options available to the patient at the point of consumption (because the rationer screens out options according to its own cost-benefit analysis). This reduction is, prima facie, undesirable. There is an intuitive pull to believe that more choice is always a good thing - or at least never a bad thing. ${ }^{30}$ Yet a variety of experimental and field studies have revealed a "paradox of choice," wherein the availability of more choice options actually decreases decision quality and satisfaction. ${ }^{31}$

Sheena Iyengar and Mark Lepper, in now-famous work, provided several controlled experimental examples of the phenomenon. ${ }^{32}$ In one study, they found that customers at an upscale grocery store were more likely to sample jams from a choice set of twenty-four flavored jam possibilities, but, paradoxically, they were actually more likely to purchase a jam when confronted with a limited set of six flavored jams only. A second study found that undergraduate students were more likely to complete an extra credit essay, and that the essays were of higher quality, if the instructor afforded only six rather than thirty topic possibilities. Subjects in a third study selected from a choice set of either six or thirty chocolates. Those in the

\footnotetext{
30 E.g., Eduardo Porter, The More Choice the Better: Yes, No or Maybe?, N.Y. TIMES (Mar. 29, 2005), http://www.nytimes.com/2005/03/28/world/americas/28iht-choice.html?_r=0 ("If you were to walk into a Wal-Mart and say to people, 'Don't you feel really depressed by having 258,000 options; shouldn't it be their obligation to reduce the choice you must endure?' They would think you were nuts.") (quoting Newt Gingrich, former speaker of the House of Representatives), archived at http://perma.cc/7WQN-LADZ

31 See generally BARRY SCHWARTZ, THE PARADOX OF CHOICE (2009).

32 Sheena S. Iyengar \& Mark R. Lepper, When Choice is Demotivating: Can One Desire Too Much of a Good Thing?, 79 J. PERSONALITY \& SOC. PSYCHOL. 995, 995-1004 (2000).
} 
limited-choice set condition were more satisfied with the taste of their chosen chocolate and experienced less regret than their counterparts confronted with the larger array of chocolates. Based on these results, the authors postulated a "choice overload hypothesis," namely, that "although the provision of extensive choices may sometimes still be seen as initially desirable, it may also prove unexpectedly demotivating in the end." 33

Subsequent empirical work has confirmed the problem of choice overload in more naturalistic settings. Proctor \& Gamble experienced a $10 \%$ increase in sales after it reduced the number of versions of Head and Shoulders shampoo from twenty-six to fifteen. ${ }^{34}$ Iyengar et al. examined enrollment rates in the $401(\mathrm{k})$ retirement benefit plans of, approximately, 800,000 employees in 650 plans across seventy industries, as a function of the number of plan options offered (which ranged from two to fifty-nine). ${ }^{35}$ Carefully controlled regression analyses revealed that, all else equal, the addition of every ten funds was associated with a $1.5-2.0 \%$ reduction in enrollment. Participation was highest when only two options were offered $(75 \%)$, but lowest when fifty-nine funds were available (60\%).

33 See also Avni M. Shah \& C. Keith Wolford, Buying Behavior as a Function of Parametric Variation of Number of Choices, 18 PSYCHOL. ScI. 369 (2007) (pens); Alexander Chernev, The Role of Purchase Quantity in Assortment Choice: The Quantity-Matching Heuristic, $45 \mathrm{~J}$. MARKETING RES. 171 (2008) (chocolates); Elena Reutskaja \& Robin M. Hogarth, Satisfaction in Choice as a Function of the Number of Alternatives: When 'Goods Satiate', 26 PsYCHOL. \& MARKETING 197-203 (2009) (gift boxes); Cassie Mogilner et al., The Mere Categorization Effect: How the Presence of Categories Increases Choosers' Perceptions of Assortment Variety and Outcome Satisfaction, 35 J. CONSUMER RES. 202-15 (2008) (coffee).

34 E. Osnos, Choking on Choices; As Options Explode, Consumers Cry, 'Less!', CHI. TRIBUNE, Sept. 7, 1997), http://articles.chicagotribune.com/1997-09-07/business/9709070121_1_ products-choices-mutual-funds, archived at http://perma.cc/S6 $\mathrm{HK}$ TDL9.

35 Sheena S. Iyengar et al., How Much Choice is Too Much?: Contributions to $401(\mathrm{k})$ Retirement Plans, in PENSION DESIGN AND STRUCTURE: NEW LESSONS FROM BEHAVIORAL FINANCE 83-95 (Olivia S. Mitchell \& Stephen P. Utkus eds., 2004). 
Why might a proliferation of options decrease choice quality and satisfaction? Several explanations have been proposed that are not mutually exclusive. ${ }^{36}$ The first is that as the number of options increases, it becomes more time consuming (and ultimately cognitively impossible) to exhaustively compare all the option attributes. A person must instead rely on simple heuristics, such as a satisficing rule. ${ }^{37}$ Although efficient, such heuristics can lead to systematic biases and, thus, relatively suboptimal choice quality. Moreover, choosers may suffer anxiety because they realize the complexity of the choice has made it impossible to choose optimally. ${ }^{38}$ A second reason is that an increased choice set might introduce multiple attractive options, which are so similar that deciding in favor of one rather than another becomes more difficult. ${ }^{39}$ Finally, counterfactual thinking and regret are more likely because a larger choice set is more likely to have an attractive second-best, non-chosen alternative.

From this perspective, outsourcing the rationing decision-and thus limiting choice-can actually provide benefits, namely, avoiding the disutility associated with choice overload. Indeed, the choice overload problem is potentially even greater in the domain of health (relative to consumer choices about jams and chocolates), since decision difficulty is typically compounded by the need to understand scientifically complex treatments, often with substantial uncertainty as to likely outcomes. Thus, whereas it might

36 See generally Benjamin Scheibehenne et al., Can There Ever Be Too Many Options? A Meta-Analytic Review of Choice Overload, $37 \mathrm{~J}$. CONSUM. RES. 409-425, 411 (2010).

37 Gerd Gigerenzer \& Wolfgang Gaissmaier, Heuristic Decision Making, 62 ANNU. REV. PSYCHOL. 451-482, 456 (2011) ("with the satisficing heuristic, the decision maker searches through options in any order, stops as soon the first option exceeds an aspiration level, and chooses this option").

38 E.g., Sheena S. Iyengar et al., Doing Better but Feeling Worse Looking for the "Best" Job Undermines Satisfaction, 17 PSYCHOL. SCI. 143 (2006).

39 E.g., Barbara Fasolo et al., Escaping the Tyranny of Choice: When Fewer Attributes Make Choice Easier, 7 MARKETING THEORY 13 (2007). 
take thirty jams to overload a consumer choice about basic food preferences, even a handful of medical treatment options might quickly exert a similar overload. ${ }^{40}$

It is worth emphasizing that the disutility emerges in two ways, namely, decision quality and decision satisfaction. Regarding quality, a patient overwhelmed with the choice might turn to a simplifying heuristic, such as just reflexively declining care or blindly deferring to her physician, who may suffer from biases of her own, including conflicting interests. ${ }^{41}$ This can result in a different-and potentially worst-decision than if a fuller consideration were given.

Although there is no direct evidence about patient decision making on this point, a study of physicians by Redelmeier and Shafir reveals the underlying psychological phenomenon. ${ }^{42}$ Physician-subjects were asked to consider an elderly patient with osteoarthritis, who will soon visit an orthopedic surgeon for possible hip replacement but in the meantime had to stop taking several attempted nonsteroidal, anti-inflammatory medications due to inefficacy or adverse effects. The decision was whether to prescribe a new medication or forgo it until the orthopedic consult. Half of subjects were told the remaining options were ibuprofen and piroxicam, while the other half were told only ibuprofen had yet to be tried. In line with a choice overload effect, $72 \%$ of subjects prescribed a drug when only ibuprofen was available, but they were less likely to prescribe a drug when both ibuprofen and piroxicam were

40 In other words, it is not the number of options per se that induces choice overload but, rather, the complexity of the choice, which is sensitive to features other than number per se.

41 Katie Beaver et al., Decision-Making Role Preferences and Information Needs: $A$ Comparison of Colorectal Cancer and Breast Cancer, 2 HEALTH EXPECTATIONS 266 (1999) (showing evidence of such deference); Christopher Robertson et al., Effect of Financial Relationships on the Behaviors of Health Care Professionals: A Review of the Evidence, 40 J.L. MED. \& ETHICS 452, 458 (2012) (showing evidence of such conflicting interests having an impact on physician decisions).

42 Donald A. Redelmeier \& Eldar Shafir, Medical Decision Making in Situations That Offer Multiple Alternatives, 273 JAMA 302 (1995). 
available. ${ }^{43}$. As the authors interpreted the finding, "[a]pparently, the uncertainty in deciding between two similar medications led some physicians to avoid this decision altogether and recommend not starting any new medication." 44

\section{B. Depletion of Cognitive Capacity}

The second alternative to cost sharing holds constant the number of choices available to the patient but eliminates the price criterion for evaluation. ${ }^{45}$ The cost- criterion can create disutility, even aside from choice overload, because of the way that it enhances the complexity of the patient's decision.

Our rationality is "bounded," as Herbert Simon explains:

Bounded rationality is simply the idea that the choices people make are determined not only by some consistent overall goal and the properties of the external world, but also by the knowledge that decision makers do and don't have of the world, their ability or inability to evoke that knowledge when it is relevant, to work out the consequences of their actions, to conjure up possible courses of action, to cope with uncertainty (including uncertainty deriving from the possible responses of other actors), and to adjudicate among their many competing wants. Rationality is bounded because these abilities are severely limited. 46

People cope with the barrage of complexity by adopting cognitive heuristics or otherwise reducing their full

$43 \quad I d$. at 304.

44 Id. at 304.

45 See supra Part F ("forgo rationing").

46 Simon A. Herbert, Bounded Rationality in Social Science: Today and Tomorrow, 1 MIND \& Soc’Y 25, 25 (2000). 
consideration of the decision problem. ${ }^{47}$ Because only a subset of information is considered, systematic biases can emerge.

Our cognitive capacity is not a static feature. The same complex decision can become more difficult-and biases more likely to emerge-as the decision maker becomes distracted, fatigued, overwhelmed with stress, and so forth. ${ }^{48}$ This is particularly relevant in the medical decision making context, where life and limb often hang in the balance and the decision maker is often making decisions in suboptimal circumstances.

More specifically, the very consideration of financial constraints can induce suboptimal decision-making. Recent research by Mani et al. is revealing on this point. ${ }^{49}$ In one experiment, shoppers at a New Jersey mall made a series of hypothetical, financial-based decisions. One scenario, for example, stated, "Your car is having some trouble and requires $\$ \mathrm{X}$ to be fixed. You can pay in full, take a loan, or take a chance and forego the service at the moment. . . . How would you go about making this decision?" 50 The amount $(\$ \mathrm{X})$ was determined by random assignment. Subjects were assigned to one of two conditions: a "hard" condition, wherein high costs were implicated (e.g., the car would take $\$ 1,500$ to fix), or an "easy" condition involving lower costs (e.g., the car would only take $\$ 150$ to fix). Subjects then completed two tests of cognitive function, and reported demographic information, including wealth. ${ }^{51}$ The

47 See generally DANIEL KAHNEMAN, ThINKING, FAST AND Slow (reprint 2013) (2011); THOMAS GILOVICH ET AL., HEURISTICS AND BIASES: THE PSYCHOLOGY OF INTUITIVE JUDGMENT (2002).

48 See generally SENDHIL MULlainathan \& ELDAR SHAFIR, SCARCITY: WHY HAVING TOO LITTLE MEANS So MuCH (2013).

49 Anandi Mani et al., Poverty Impedes Cognitive Function, 341 SCIENCE 976 (2013).

$50 \quad$ Id. at 976.

51 Id. at 977 ("Raven's test is a common component in IQ tests and is used to measure 'fluid intelligence,' the capacity to think logically and solve problems in novel situations, independent of acquired knowledge. The spatial incompatibility task requires participants to respond quickly and often contrary to their initial impulse.") (internal citations omitted). 
central finding was an interaction effect of task difficulty and the respondent's wealth on cognitive performance. In particular, "poor" and "rich" subjects performed equally well on the cognitive tests following easy decisions; after hard decisions that evoked onerous financial situations, in contrast, the poor subjects performed substantially worse..$^{52}$ As the authors interpreted it, "[p]reoccupation with pressing budgetary concerns leaves fewer cognitive resources available to guide choice and action." 53

Three additional experiments replicated Mani's finding, as well as ruled out alternative explanations, such as math anxiety, a lack of real-world financial incentive, or that the cognitive tests themselves induced undue cognitive load. It also confirmed the effect size was substantial.54 The effect is akin to what sleep researchers observe after a subject suffers a full night of sleep deprivation; the performance difference between chronic alcoholics and normal adults; or a thirteen-point decrease in IQ. ${ }^{55}$ In other words, consideration of stressful financial constraints can seriously undermine cognitive performance. The authors warn that "policy-makers should beware of imposing cognitive taxes on the poor just as they avoid monetary taxes on the poor." 56 Accordingly, the imposition of cost sharing may actually reduce the patient's ability to think carefully about the other attributes of her healthcare choices.

A different thread of research has focused, not on financially induced mental constraints, but more generally on the effects of depleted mental resources. Fatigue, for instance, can seriously undermine the ability to think critically, even about important life decisions. Consider the willingness of judges to grant a parole request. This requires an active decision, in the sense that greater mental effort is required to justify an exception to the default rule of maintaining the a priori sentence. One field study of Israeli judges found that the proportions of parole grants

$\begin{array}{ll}52 & I d . \\ 53 & I d . \text { at } 976 . \\ 54 & \text { Cohen's d ranged from } 0.88 \text { to } 0.94 . \text { Id. at } 977 . \\ 55 & I d . \text { at } 980 . \\ 56 & I d \text {. at } 980 .\end{array}$


was tightly coupled with number of hours since the judge last took a break. ${ }^{57}$ As the time lengthened-and thus the judge became more fatigued-it became significantly less likely that the parole request would be granted. As soon as a break occurred, the proportion of parole grants returned to the same rate seen at the beginning of the morning.

These threads of research are suggestive for the understanding the cognitive effects of cost-sharing burdens in healthcare. Consideration of financial costs has the potential to undermine a fuller consideration of the nonfinancial choice features, such as likelihood of outcomes and quality of life. This is not to suggest that mental effort should not be spent on considering the financial constraints. Rather the question is who: whether the patient, or someone else should be making this exertion. Cost sharing may not be the most efficient allocation of effort.

Patients sense this difficulty: research has shown that U.S. health consumers are equivocal about the idea of discussing costs with physicians "in the clinical encounter." 58 In focus groups conducted by Sommers and colleagues, one respondent explained that when costs are introduced into the doctor-patient conversation, her reaction is to say, "I don't care! Just fix my problem." 59 Another said, "All that's all well and good until you actually find yourself in a life-or-death situation, and you'll really see you're not even going to be concerned about the cost." 60 Patient may rationally prefer to ignore this factor, and, thus, rationally prefer a healthcare system that either outsources those considerations (at the sacrifice of options) or mutes them altogether (at the sacrifice of wealth).

57 Shai Danziger et al., Extraneous Factors in Judicial Decisions, PROC. NAT'L ACAD. SCI. U.S. AM. 6889, 6889 (2011).

58 Roseanna Sommers et al., Focus Groups Highlight That Many Patients Object To Clinicians' Focusing On Costs, 32 Health AFF. (Millwood) 338 (2013).

$59 \quad I d$. at 343.

$60 \quad I d$. 


\section{Facilitation of Regret}

The facilitation of regret may be another way in which cost sharing causes subjective disutility. Richard Thaler has argued that, similarly to tourists preferring a resort that includes food and drink in the cost, health insurance buyers "choose not to choose" by sinking the costs of healthcare, so that at the point of consumption, they need not make choices about money in ways that they may later potentially regret. ${ }^{61} \mathrm{~A}$ similar dynamic applies to health consumption:

Consider a couple which must decide whether to spend $\$ \mathrm{X}$ for a diagnostic test for their child. There is some small probability $p$ that the child has a serious disease which could be treated if detected early enough. There will surely be regret if the decision is made not to get the test and the child later is found to have the disease. If the disease can be fatal, then the regret may loom so large that the test will be administered even for very large values of $\mathrm{X}$ or very small values of $p$. Yet once the test is ordered and the likely negative result is obtained, the couple may regret the expenditure, especially if it is large relative to their income. Obviously, these costs are avoided if all health care is prepaid, via either first dollar coverage or a prepaid health organization. ${ }^{62}$

Thaler goes on, however, to explain that this regret dynamic is not peculiar to out-of-pocket spending, but arises whenever there is a difficult decision. When there are two different surgical procedures from which to choose, "[c]learly in this situation a rational consumer would want the physician to make the choice and furthermore, he would not

61 Richard Thaler, Toward a Positive Theory of Consumer Choice. 1 J. ECON. BEHAV. \& ORG. 39, 53 (1980).

62 Id. 
want to know that a choice existed!"63 That way, patients that suffer a bad outcome need not experience any regret. On this analysis, then, cost sharing is not itself problematic; rather, it is the difficulty of the decision that is problematic. Still, the elimination of cost sharing by removing options or option attributes has the potential to avoid regret.

Terry Connolly and colleagues, through a series of careful laboratory experiments, have delineated several different types of regret. ${ }^{64}$ Noting that regret is a transitive verb-one typically regrets something-there is a distinction based upon the target of regret. With outcome regret the target is the outcome of the decision, whereas option regret focuses on the particular decision made, and process regret targets the way in which the decision was made, including the factors considered, information gathered, and time consumed. Consider a patient who foregoes implantation of a surgical stent and then, months later, suffers a heart attack. The patient might experience regret: that the heart attacked occurred (outcome regret); that she chose stent over drugs (option regret); that he or she did not more carefully consider the pros and cons of implanting the stent (process regret); or any combination of these. The key difference is that process regret, unlike outcome regret, is "centrally concerned with mechanisms of self-criticism and justification."65 More particularly, when a poor decision outcome occurs, "individuals tend to ask themselves whether the decision, or the process that led up to it, was justified; if it was partially or entirely unjustified, we feel regret, the intensity of which is increased by the seriousness of the outcome." 66

These dynamics have only begun to be studied in the healthcare context, and we have found no research has

$63 \quad I d$.

64 Terry Connolly \& Jochen Reb, Regret Aversion in Reason-Based Choice, 73 THEORY DECIS. 35 (2012) (reviewing studies).

65 Terry Connolly \& Marcel Zeelenberg, Regret in Decision Making, 11 CURRENT DiRECTIONS PSYCHOL. SCI. 212, S31 (2002).

66 Id. 
focused on cost sharing in particular. ${ }^{67}$ We do know that regret is a common phenomenon in healthcare, however. ${ }^{68}$ As Connoly and Reb review the literature, "Regret about treatment decisions was associated with worse current health related quality of life in men with localized prostate cancer and with worse generic and prostate-cancer-related quality of life and emotional well-being in men treated for metastatic prostate cancer, although the causal direction of the relations found in these studies remains uncertain."69

Of course, in healthcare, there will always be bad outcomes, with or without cost sharing. Plausibly, though, when a self-rationing cost-sharing scheme is replaced by an other-rationing scheme, a patient can be shielded from process regret, even while suffering bad outcomes. Process regret is shielded, if the decision is outsourced to somehow else. If a treatment is declined, a patient might regret any ensuing bad outcome, but he or she will not be in a position of feel the pang of self-blame that is process regret. ${ }^{70}$ If the other-rationer also prevents the patient from becoming aware of other options, she may also thereby avoid option regret. ${ }^{71}$ Cost sharing thus arguably increases these psychic costs.

67 See Terry Connolly \& Jochen Reb, Regret in Cancer-Related Decisions, 24 HEALTH PSYCHOL. S29 (2005) (outlining directions for future research).

68 See e.g., E. P. Winer, et al. Silicone controversy: $A$ survey of women with breast cancer and silicone implants, 85 J. NAT'L CANCER INSTITUTE, $85,1407-11$ (1993) (showing that $34 \%$ of those who had received silicon implants would now be completely unlikely to choose them, while only $16 \%$ reported regrets about the reconstruction).

69 Connolly \& Reb, supra note 64, at S32 (internal citations omitted).

70 See Stacey L. Sheridan, Shared Decision Making About Screening And Chemoprevention, 26 AM. J. PREventive MED., 56, 60 (2004) (discussing "fear of regret for decisions that turn out badly" as one reason patients do not seek to be involved in decision making).

71 See Marco Boeria et al., The role of regret minimisation in lifestyle choices affecting the risk of coronary heart disease, $32 \mathrm{~J}$. HEALTH ECON. 253, 253 (2013) (providing data from a discrete choice experiment, which support the conception of regret as "defined as what one experiences when a non-chosen alternative in a choice set performs better than a chosen one"). 


\section{CONCLUSIONS}

We have distinguished between several normative objections to the trend of asking patients to take responsibility for a portion of the costs of their healthcar and mined the potential problem that cost sharing may impose a "decisional burden." We identified the appropriate counterfactuals for thinking about the causal effects of cost sharing along this dimension and reviewed three potential mechanisms of disutility: choice overload, depletion of cognitive capacity, and facilitation of regret. We conclude that the decisional burden of cost sharing is a real problem.

Nonetheless, the behavioral science results are descriptive, not prescriptive. And we are unable to compare the size of this disutility with the diminishment of choices that comes with outsourcing the rationing function or the runaway costs that come with simply foregoing the rationing function altogether. This difficulty may explain why different political communities reach different conclusions about these ultimate questions.

Advocates of cost sharing must pay closer attention to these disadvantages of this particular mechanism for rationing healthcare. Indeed, perhaps sustained attention will yield ways to improve the mechanisms of cost sharing so as to reap its advantages while minimizing some of these psychic costs.

Regardless, in a world of epistemic uncertainty and heterogeneity of values, it is not irrational for consumers to prefer cost sharing-if carefully designed and implemented-as the least-bad rationing mechanism among the alternatives, which either reduce access to healthcare or sink costs for unwanted healthcare. There may be a tradeoff here between autonomy and utility. George Bernard Shaw famously said that, "liberty means responsibility. That's why most men dread it." Ultimately, the burden of deciding for yourself is the burden of being an autonomous person. 